\title{
Using a problem-based approach to teach statistics to postgraduate science students: A case study
}

Thomas Jaki

Department of Mathematics and Statistics

Lancaster University

jaki.thomas@gmail.com

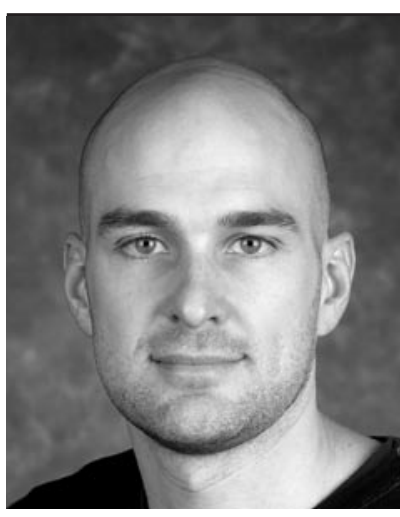

Melanie Autin

Department of Mathematics and Computer Science Western Kentucky University melanie.autin@gmail.com

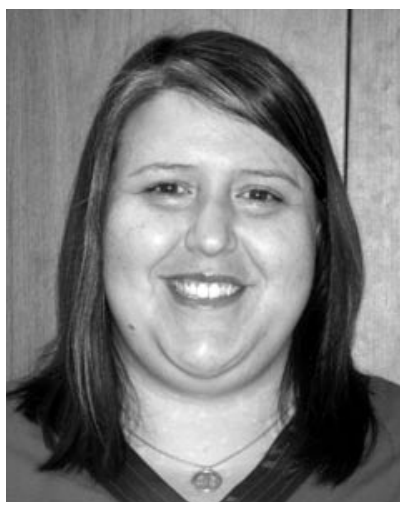

The standard approach to teaching statistics is teacher-centered in which the lecturer tries to impose his knowledge onto the students. This method forces a particular learning style and pace on students, and students often fail to make the connection of when various statistical methods are appropriate. Here we discuss a statistics course for non-specialist postgraduate students at Lancaster University that uses a problem-based learning approach.

\section{Introduction}

Traditional classroom instruction consists of teacher-centered learning in which the instructor presents course material through lectures. A recent trend in higher education is the implementation of student-centered learning in which students take a more active role in the learning process. One such method is problem-based learning (PBL), which was developed in the 1960s in the field of medical education [1]. $\mathrm{PBL}$ is defined by Boud and Feletti [2] as "a way of constructing and teaching courses using problems as the stimulus and focus for student activity". Instead of presenting the material through a traditional lecture format, students discover the material themselves through the exploration of a real-world problem or scenario. The instructor fills the role of a facilitator rather than a lecturer. In the past, most PBL courses were held in medical schools, but in recent years a variety of other subjects have started to experiment with this approach.

In this manuscript we will discuss our experiences of a problem-based course in statistics for postgraduate students in science. Since statistics is not the primary area of study for these students, we felt that using a PBL approach would allow students to focus on the use of statistical methods rather than the theory behind them, as it will be important for these students to know how to find appropriate statistical methods and interpret the results in their future careers. Using PBL allows them to learn how to explore which statistical methods are appropriate in various situations. We will proceed with some additional details on PBL, before we describe the structure of the course and the implementation of PBL. We then reflect on the course experiences of both the instructor and the students before we end with some concluding remarks.

\section{Problem-based learning}

PBL was first introduced in the medical school at McMaster University in Canada in the 1960s. Instead of learning information from the typical teacher-centered didactic curriculum, students solved clinical problems in order to gain knowledge. These clinical problems were designed to mimic the situations that will arise when these students become medical professionals. In the 1980s, PBL extended naturally to other 
health-related disciplines, such as pharmacy, nursing, and veterinary medicine [3]. It began to expand outside of the health fields in the 1990s, gaining popularity in the arts, humanities, and sciences. It is also during this time that PBL began to appear in statistics courses $[4,5]$.

One long-established educational practice involves lecturing students on a topic; this is followed with problems for the students to solve using the methods presented. In $\mathrm{PBL}$, students are not given instruction prior to the problem. Student teams must determine what knowledge they lack for solving the problem. They are then required to fill this knowledge gap through self-directed learning. Thus, it is necessary that students have access to materials that assist them, namely libraries and computers. The instructor, often called the facilitator, serves not as a source for solving the problem, but as a guide through the group-learning process. The facilitator guides the students through strategies for learning and thinking, rather than through the content itself [6].

Although there are slight variations of PBL models, there are several common characteristics [7]:

- Use of complex, real-world scenarios that possibly have multiple approaches and solutions.

- No instruction is given on how to solve the problem; students use self-directed learning to solve the problem and to gain new knowledge.

- Students work in small teams to solve the problem - the instructor acts as a facilitator.

- Problem-solving skills are developed through the exploration of the problem.

Since PBL requires that students take an active part in their own learning, it is best suited for motivated students that have the desire to take accountability for their own learning; PBL is not for students that do not have the self-discipline to discover new information without an instructor giving it to them. However, with practice, PBL students can become more self-reliant [6].

\section{A statistics course for science postgraduate students}

In the Faculty of Science and Technology at Lancaster University a variety of different courses are offered to postgraduate students under the title 'Doctoral development program' These courses are aimed to provide postgraduate research students training on topics such as academic writing and presentation skills and to allow postgraduate students to achieve the 10 training days per year they are expected to complete according to the code of practice of the Quality Assurance Agency in Higher Education [8]. Since these courses are not associated with a certificate or degree, there is no formal assessment of the work in the course required. The course that will be described here, 'Statistical Methods in Scientific Research', is part of this program. The course is geared to develop the skills of the students to transform a research question into a measurable question and to identify an appropriate statistical methodology to test the question at hand. In particular, the defined outcomes of the course are:

- to provide students with a basic understanding of the role statistics can play in scientific research,

- to introduce students to the central ideas in experimental design, inference and modelling,

- to prepare students for further reading and/or more specialized courses in statistical topics appropriate to their particular area of research.

Resulting from the above aims together with the wide range of areas of study (Figure 1), we decided that it was more beneficial for the students to learn the process of finding an appropriate statistical methodology rather than teaching the details of different methods; we therefore decided to adopt a problem-based learning approach for this course. Another advantage of using a problem-based approach was that it mimics the process students are facing during their studies towards a masters degree or PhD. Furthermore, as it would be nearly impossible to cover every statistical method that could arise in the students' research, we felt it was better that they learn how to explore statistical methods on their own.

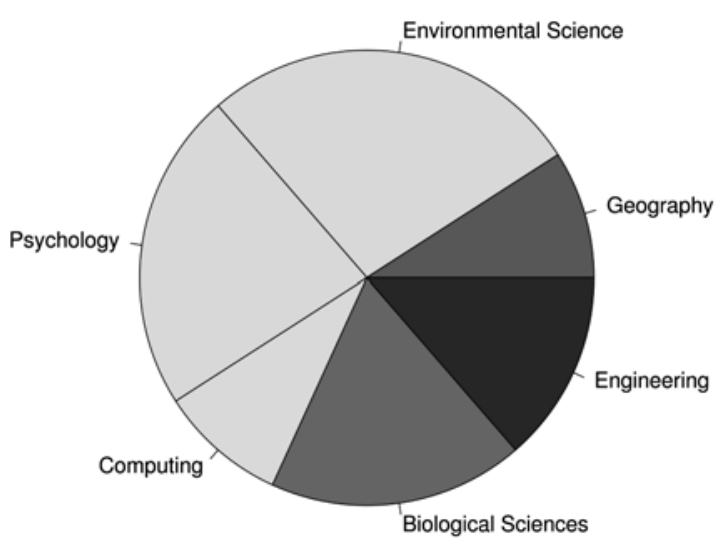

Figure 1: Enrolled students' field of study.

The course was held as an intensive course on three consecutive days and was comprised of 22 students, 21 of them pursuing a $\mathrm{PhD}$ and one student working on his master's degree (MSc). Each day was split into two threehour sessions, during each of which a different scenario was investigated. For each session a one-page description of a problem was prepared (see Appendix A for an example) and, when appropriate, a corresponding dataset included. Each scenario contained some information regarding the problem at hand together with some topics that might be useful to consider. We decided to include these 'topics to consider' to help students that, as a whole, were unfamiliar with the idea of PBL to get started. The statistical topics associated with the six problems were:

- Experimental design, 
- Hypothesis testing,

- Regression modelling,

- Survival analysis,

- Generalized linear models,

- Time series.

During each three-hour session, the students worked on the scenario for around 2 hours in self-selected groups of five. The remaining hour of each session was used to discuss solutions obtained by the different groups and to clarify a few details on statistical methodology, if necessary. In order for the students to access different resources for relevant information, the course was held in a computer lab to provide internet access; in addition, students were allowed to use the statistics library and main library of the university. A further reason for the use of a computer lab was to allow students to use SPSS [9] or similar statistical software of their choosing. One possible solution to each scenario had been prepared and was made available after each session. The solution also included a step-by-step guide on how to obtain the desired results in SPSS whenever appropriate.

To provide the students with an additional opportunity to develop their statistical abilities, the course also included an optional assessment. The rationale was to personalise the course to fit the individual needs of each student by relating the material closer to their $\mathrm{MSc} / \mathrm{PhD}$. The assessment comprised of a one-thousand-word report and an annotated bibliography. The report was due within 2 weeks of completion of the course and dealt with the statistical aspects of a topic of the student's choice. It was anticipated that students would choose a topic that is either a part of or closely related to their PhD/MSc work. The report consisted of a description of the research question of interest and focused on how to statistically answer that question. A discussion about the collection of appropriate data, ideas for an appropriate statistical methodology and what results would support the question asked were expected. It was not expected, however, that any data would be collected or analysed for this report. The marking and feedback of the report, consequently, would act as free statistical consultation on the appropriateness of the ideas of the students.

To ensure that students who opted to complete the optional assignment did approach their search for an appropriate statistical technique in a scientific manner, they also submitted an annotated bibliography (a bibliography with a short description of the content of each item). This annotated bibliography aims to foster "active engagement with learning tasks" [10]. A further reason for the requirement of an annotated bibliography was to familiarise the students with literature review, a specific outcome defined for this course. It was required that the annotated bibliography consisted of at least three items for each of

- the scientific background of the problem;
- the statistical methodology;

- proposed solutions to this or a related problem.

\section{Students feedback and other comments}

In this section we will discuss the experiences with the course and provide some student comments as obtained via a feedback form. One of the biggest challenges going into this course was thought to be the diverse statistical background of the students. In fact, $10 \%$ of students reported that they had no prior knowledge of statistics while another $15 \%$ classified their prior knowledge as advanced. PBL, however, appeared to appropriately address this issue as it made it possible for students to adjust the level of learning according to their prior knowledge and even focus their attention on topics more relevant for their specific subject. Furthermore, several students indicated in personal discussion that working as a group allowed them to engage with material that they felt they did not have the required background knowledge for.

There were, however, some minor issues regarding the implementation of the group work. As the course was held in a computer lab, group discussion was hindered since the computers made for a large obstacle; only one of the groups decided to use the available open space in the lab to form a circle away from the computers. Furthermore, the availability of the computers made students start with individual internet searches instead of discussing the problem with their peers. In retrospect, it therefore would have been better to decrease the group size to three or four and to make only one notebook computer available per group in order to stimulate the discussion amongst students. This could have been easily achieved by the use of a flexible or mobile computer lab.

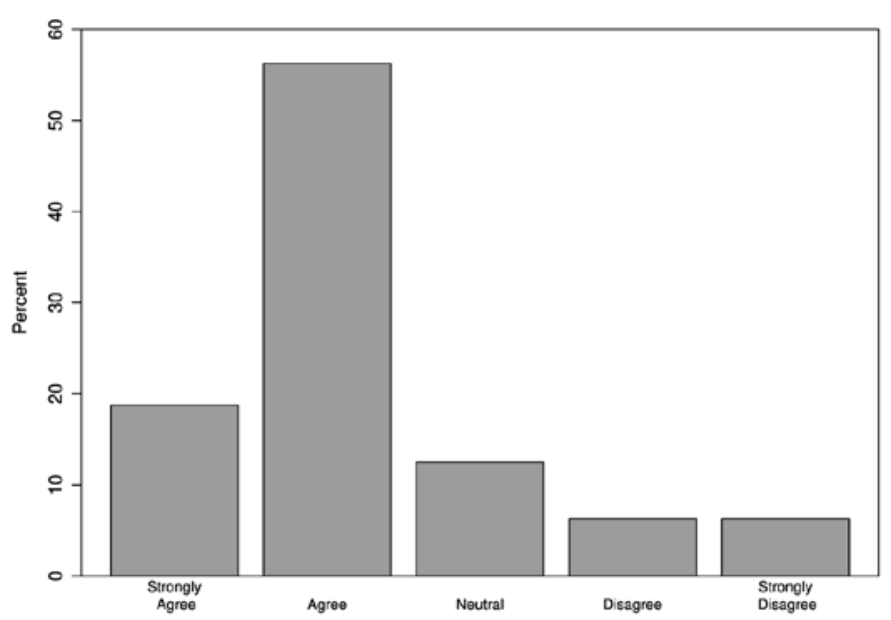

Figure 2: Responses for "The method of teaching was appropriate for this course" in the student feedback form.

Aside from the above teething problems of this newly developed course, the course went very well. Of the 16 students that provided feedback, 12 students agreed or strongly agreed that they would recommend the course to other students, and only 2 students thought that a traditional lecture format would have been better. To the question of 
whether they found this course to be useful for their graduate research, only one student disagreed while the majority (56\%) of students agreed or strongly agreed. Regarding the use of PBL in this course, about $75 \%$ of students agreed that the method of teaching was appropriate for the course (Figure 2 ) and that sufficient guidance was given for each scenario. Interestingly, the results (given in Table 1) for the question "As the course progressed, I became more comfortable with undertaking the set tasks" suggest that about half of the class did not get more comfortable with the problem-based learning approach. In combination with the above positive feedback, however, it appears that those students still consider the PBL approach to be worthwhile and beneficial, even though they were working in unfamiliar territory.

\begin{tabular}{|l|l|}
\hline Response & Frequency \\
\hline Strongly Agree & 1 \\
\hline Agree & 5 \\
\hline Neutral & 3 \\
\hline Disagree & 6 \\
\hline Strongly Disagree & 0 \\
\hline
\end{tabular}

Table 1: Responses for "As the course progressed, I became more comfortable with undertaking the set tasks" in the student feedback form.

A few interesting insights can also be obtained from the open answer questions. Among the things that students liked about this course, the use of examples and the "learning by doing" approach was mentioned several times. Even more positive responses can be found of students' opinions on the use of real-world problems, where the answers ranged from "I think this is essential" to "It's why we do stats.... it makes stats accessible to other disciplines." Among the things that the students disliked about the course were: a lack of taught theory and some frustration with attempting (or failing to attempt) to find a solution for the scenarios by themselves.

The aspect of the course that we were most unsure about before its start was the optional assessment. Although we felt that students would greatly benefit from completing the assessment, we had great doubts if anyone would even attempt to complete it, as it was not required. From the feedback form we found that only three students planned on completing the report and another five were undecided at this point. Furthermore, students were undecided if a report was the appropriate method to assess this course but felt more positively about the annotated bibliography. Ultimately, six students did complete the optional report and annotated bibliography with five of the reports being of exceptionally high standard. The fact that all students submitted more than the minimum required number of items with the annotated bibliography suggests that this piece of assessment was perceived to be integral for the report.

\section{Discussion}

In this manuscript we discuss an implementation of a problem-based learning approach in a postgraduate course in statistics for students of a science subject. A variety of scenarios were presented to the students who, in small groups, investigated appropriate statistical methods to answer the scientific question associated with each scenario. The idea was to mimic the process that these research students have to undergo for their theses as closely as possible.

Based on our experience with this course, we found that this problem-based learning approach worked well for this set of students because it coped with differing levels of prior knowledge and interests since the students were in charge of their own learning. In addition to our own judgement, the student feedback indicates that the PBL approach was also positively received by the students. The feedback also demonstrated that the fact that the entire course was motivated through examples was much appreciated. This point in particular suggests that a wider adoption of problem-based statistics courses could be appropriate. We feel that, especially for courses for non-statistics majors (service courses), a problem-based approach can be useful as it eliminates the constant question about the usefulness of statistics. In addition, students can emphasize their learning on the concepts and interpretations rather than the mathematical details according to their personal strengths.

A different aspect to this course was the assessment strategy which was aligned closely with the learning objectives of the course. In particular, the use of an annotated bibliography appeared to have a positive impact; thus, we will certainly include it as part of future courses for formative assessment.

\section{References}

1. Barrows, H.S. and Tamblyn, R. (1980). Problem-Based Learning: An Approach to Medical Education, New York: Springer.

2. Boud, D. and Feletti, G. (1997). The Challenges of ProblemBased Learning ( $2^{\text {nd }}$ edition), London: Kogan Page.

3. Savin-Baden, M. and Major, C.H. (2004). Foundations of Problem-based Learning, Maidenhead: Society for Research into Higher Education \& Open University Press.

4. Boyle, C.R. (1999). “A Problem-Based Learning Approach to Teaching Biostatistics," Journal of Statistics Education, 7, http://www.amstat.org/publications/jse/ secure/v7n1/boyle.cfm

5. Hillmer, S.C. (1996). "A Problem-Solving Approach to Teaching Business Statistics," The American Statistician, 50, 249-256.

6. Hmelo-Silver, C.E. (2004). "Problem-Based Learning: What and How do Students Learn?" Educational Psychology Review, 16, 235-266.

7. Barrows, H.S. (1986). "A Taxonomy of Problem-Based Learning Methods," Medical Education, 20, 481-486. 


\section{Continued from page 43}

8. The quality assurance agency for higher education (2004). Code of practice for the assurance of academic quality and standards in higher education. Section 1: Postgraduate research programmes. ISBN 184482168 4 Last accessed 28 April 2008 at http://www.qaa.ac.uk/ academicinfrastructure/codeOfPractice/section1/ appendix.asp\#append3

9. SPSS Inc. (2005). SPSS Base 14.0 for Windows User's Guide. SPSS Inc., Chicago IL.

10. Ramsden, P. (2003). Learning to Teach in Higher Education ( $2^{\text {nd }}$ edition), Routledge, UK.

\section{Appendix}

\section{A. Example Scenario}

\section{Improving Memory}

Dr. Pepe Roni, a researcher in memory psychology, believes that the amount of available energy impacts the memory in humans during the memorization phase. In particular, he argues that a higher glucose-level in the bloodstream prior to studying has positive effects on both the long and shortterm memory. To validate his claim, he wants to perform an experiment to test if this effect does exist in reality. Having no prior experience in Statistics, he has turned to you for your help. Can you help him design an experiment to test his claim?
The steps for implementing a good experimental study:

1. Identify the problem and define it in simple words

2. Construct hypotheses related to the problem

3. Construct an experimental design which takes into account possible conditions which may arise in the experiment

4. Conduct the experiment, following the pre-defined experimental design

5. Compile the observed data into a usable form

6. Apply appropriate statistical methodology

7. Conclude by stating the findings in a clear way relating back to the original problem.

In this problem the goal is to design the experiment only. This is, however, only possible with the above steps in mind.

\section{Topics to consider:}

- Experiment or observational study?

- Principles of experimental designs

- Population versus Sample

- Parameter versus Estimator

-What makes a good estimator?

- How can you decide if Dr. Roni's claim is true? 